\title{
AUMC Over Dosing Interval Normalized by Weight
}

National Cancer Institute

\section{Source}

National Cancer Institute. AUMC Over Dosing Interval Normalized by Weight. NCI

Thesaurus. Code C92341.

The area under the first moment curve (AUMC) for the defined interval between doses (TAU) divided by the weight. 